Research Applications:Recommendations of the International RDC/TMD Consortium Network (International Association for Dental Research) and Orofacial PainSpecial Interest Group (International Association for the Study of Pain) // J Oral Facial Pain Headache. 2014; 28,1:6 - $27 . \quad$ e-link: https://www.ncbi.nlm.nih.gov/pubmed/24482784
6. Wilkes C.H. Internal derangements of the temporomandibular joint. Pathological variations. Arch Otolaryngol Head Neck Surg. 1989; Apr;115(4): 469-77. e-link: https://www.ncbi.nlm.nih.gov/pubmed/2923691.

Надійшла 17.01.19

УДК [616.316-008.8+577.1]:616.314-089.23

DOI https://doi.org/10.35220/2523-420X/2019.1.6

Ю.В. Горохивская, О.В. Деньга, д. мед. н., О.А. Макаренко, д. биол. н.

Государственное учреждение «Институт стоматологии и челюстно-лицевой хирургии Национальной академии медицинских наук Украины»

\title{
БИОХИМИЧЕСКИЕ ПОКАЗАТЕЛИ РОТОВОЙ ЖИДКОСТИ ДЕТЕЙ В ДИНАМИКЕ ОРТОДОНТИЧЕСКОГО ЛЕЧЕНИЯ СЪЁМНЫМИ АППАРАТАМИ
}

Проведенные исследования показали, что разработанный лечебно-профилактический комплекс, включавший адаптоген «Леквин», набор витаминов и микроэлементов «Пиковит плюс», гель «Квертулидон» и зубной эликсир «Лизодент», при лечении зубочелюстных аномалий у детей со средним кариесом зубов с использованием съёмных аппаратов обладает выраженным минерализуюшим, антиоксидантным и регулирующим микробиоченоз действием. При этом в ротовой жидкости детей основной группь за 2 года наблюдений достоверно увеличивались по сравнению с исходным состоянием и группой сравнения содержание кальция и фосфора, активность лизоцима, каталазы и уменьшались активность уреазы, эластазы и содержание малонового диальдегида.

Ключевые слова: дети, ортодонтическое лечение, съёмные аппараты, ротовая жидкость, биохимические показатели.

\section{Ю.В. Горохівська, О.В. Дєньга, О.А. Макаренко}

Державна установа «Інститут стоматології та щелепно-лицевої хірургії Національної академії медичних наук України»

\section{БІОХІМІЧНІ ПОКАЗНИКИ РОТОВОЇ РІДИНИ ДІТЕЙ В ДИНАМІЦІ ОРТОДОНТИЧНОГО ЛІКУВАННЯ ЗНІМНИМИ АПАРАТАМИ}

Проведені дослідження показали, щзо розроблений лікувально-профілактичний комплекс, щзо включав адаптоген «Леквін», набір вітамінів і мікроелементів «Піковіт плюс», гель «Квертулідон» $i$ зубний еліксир «Лізодент», при лікуванні зубощелепних аномалій у дітей із середнім карієсом зубів із використанням знімних апаратів має виражену мінералізуючу, антиоксидантну і регулюючу мікробіоценоз дію. При цььому в ротовій рідині дітей основної групи за 2 роки спостережень достовірно збільшувалися в порівнянні з вихідним станом $i$ групою порівняння вміст кальцію і фосфору, активність лізоциму, каталази і зменшувалися активність уреази, еластази і вміст малонового діальдегіду.

Ключові слова: діти, ортодонтичне лікування, знімні апарати, ротова рідина, біохімічні показники. 


\title{
Y.V. Gorokhivskaya, O.V. Denga, O.A. Makarenko
}

State Establishment «The Institute of Stomatology and Maxillo-Facial Surgery National Academy of Medical Science of Ukraine»

\section{BIOCHEMICAL PARAMETERS OF CHILDREN'S ORAL LIQUID IN DYNAMICS OF ORTHODONTIC TREATMENT WITH REMOVABLE APPLIANCE}

\begin{abstract}
Studies have shown that developed treatment and prophylactic complex, which included "Lekvin" adaptogen, a set of vitamins and microelements "Pikovit plus", "Quertulidon" gel, and "Lizodent" elixir, in treatment of dental anomalies in children with moderate dental caries and removable appliances has a pronounced mineralizing, antioxidant and microbiocenosis-regulating action. At the same time, over 2 years of observation oral liquid main group children significantly increased the content of calcium and phosphorus, activity of lysozyme, catalase and the urease, elastase and malonic dialdehyde levels compared with the initial state and comparison group.
\end{abstract}

Key words: children, orthodontic treatment, removable appliances, oral liquid, biochemical parameters.

Применение съёмных ортодонтических аппаратов оказывает негативное влияние на ткани пародонта и состояние гигиены полости рта у детей [1]. Съёмный аппарат вызывает нефизиологические механические нагрузки на пародонт и осложняет уход за полостью рта. Эта конструкция является длительным раздражителем, результат которого на ткани пародонта определяется состоянием неспецифической резистентности. Ситуация значительно усугубляется наличием кариозных зубов в полости рта и гингивитом [2].

Цель данного исследования. Оценка эффективности разработанного лечебнопрофилактического комплекса (ЛПК) при ортодонтическом лечении у детей 6-7 лет зубов со средним кариесом.

Mатериалы и методы. Было проведено исследование изменений под действием ЛПК биохимических маркеров ротовой жидкости у детей при ортодонтическом лечении зубов временного прикуса.

Перед фиксацией ортодонтической аппаратуры у детей группы сравнения (22 человека) и основной группы (25 человек) были проведены санация полости рта и профилактическая гигиена.

Кроме того, дети основной группы после проведенной санации полости рта и профилактической гигиены перед фиксацией съёмного аппарата в течение 2-х недель 2 раза в году получали по инструкции ЛПК, состоявший из адаптогена «Леквин», набора витаминов и микроэлементов «Пиковит плюс» и местного применения на ночь геля «Квертулидон», обладающего антиоксидантными свойствами, регулирующего микробиоценоз в полости рта. В течение дня дети ополаскивали рот эликсиром «Лизодент» (2 ч.л. на $1 / 4$ стакана воды).

После фиксации аппарата дети обеих групп дважды в день утром и вечером чистили зубы зубной пастой «Lacalut 4-8».

В процессе исследования оценивалось влияние ЛПК на антиоксидантную систему (АОC), состояние неспецифической резистентности полости рта, микробиоценоз полости рта, воспаление и содержание кальция $(\mathrm{Ca})$ и фосфора $(\mathrm{P})$ в ротовой жидкости [3-9].

Результаты и их обсуждение. Уровень кальция в ротовой жидкости детей основной группы и группы сравнения после санации полости рта и профилактический гигиены достоверных изменений не претерпел. В группе сравнения на всех этапах исследования ротовой жидкости детей содержание кальция соответствовало исходному низкому уровню $[6,9]$. У детей основной группы, получавших ЛПК, содержание Са достоверно повысилось уже через 1 месяц после фиксации аппарата. Через полгода уровень Са в основной группе был в 2 раза выше исходного, оставаясь на этом уровне и через 2 года (табл. 1).

Возрастание содержания $\mathrm{P}$ в ротовой жидкости детей основной группы было отмечено уже через 6 месяцев после фиксации аппарата и также сохранялось на высоком уровне через 1 и 2 года. Содержание $\mathrm{P}$ в ротовой жидкости детей группы сравнения практически не изменилось на всех этапах наблюдения (табл. 2).

Условно-патогенная микрофлора, которая способствует возникновению кариеса зубов, оценивалась по уровню активности уреазы, выделяемой ею (табл. 3) [5, 8].

Проведение лечебно-профилактических мероприятий перед началом ортодонтического лечения позволило снизить активность уреазы в 8 раз в основной группе и в 2,5 раза в группе сравнения. В основной группе этот показатель оставался и через 1 и 2 года ниже исходных значений и данных группы сравнения.

Оценку состояния неспецифической резистентности у детей мы проводили по одному из 
антимикробных факторов полости рта - лизоциму (табл. 4). Исходные данные свидетельствуют о невысокой активности этого фермента в ротовой жидкости детей обеих групп, т.е. о не высоком уровне неспецифической резистентности. В основной группе перед началом ортодонтическо- го лечения активность лизоцима увеличилась за счёт лечебно-профилактических мероприятий в 1,5 раза, а через полгода - в 2,8 раза. Через 1 и 2 года наблюдения активность лизоцима в этой группе была достоверно выше, чем на исходном уровне и чем в группе сравнения.

Таблица 1

\section{Содержание кальция в ротовой жидкости детей на разных этапах ортодонтического лечения, ммоль/л}

\begin{tabular}{|l|c|c|c|}
\hline \multicolumn{1}{|c|}{ Сроки } & $\begin{array}{c}\text { Группа сравнения, } \\
\mathrm{n}=22\end{array}$ & $\begin{array}{c}\text { Основная } \\
\text { группа, } \\
\mathrm{n}=25\end{array}$ & $\mathrm{p}$ \\
\hline Исходный & $0,53 \pm 0,05$ & $0,62 \pm 0,06$ & $\mathrm{p}>0,1$ \\
\hline $\begin{array}{l}\text { Через 2 недели профилактики перед фикса- } \\
\text { цией пластинки }\end{array}$ & $\begin{array}{c}0,57 \pm 0,08 \\
\mathrm{p}_{1}>0,1\end{array}$ & $\begin{array}{c}0,76 \pm 0,07 \\
\mathrm{p}_{1}>0,1\end{array}$ & $\mathrm{p}>0,1$ \\
\hline Через 1 месяц после фиксации пластинки & $\begin{array}{c}0,65 \pm 0,07 \\
\mathrm{p}_{1}>0,1\end{array}$ & $\begin{array}{c}0,84 \pm 0,09 \\
\mathrm{p}_{1}<0,001\end{array}$ & $\mathrm{p}<0,05$ \\
\hline Через 6 месяцев после фиксации пластинки & $\begin{array}{c}0,70 \pm 0,05 \\
\mathrm{p}_{1}>0,1\end{array}$ & $\begin{array}{c}1,10 \pm 0,08 \\
\mathrm{p}_{1}<0,001\end{array}$ & $\mathrm{p}<0,001$ \\
\hline Через 1 год после фиксации пластинки & $\begin{array}{c}0,73 \pm 0,07 \\
\mathrm{p}_{1}>0,1\end{array}$ & $\begin{array}{c}1,09 \pm 0,07 \\
\mathrm{p}_{1}<0,001\end{array}$ & $\mathrm{p}<0,001$ \\
\hline Через 2 года после фиксации пластинки & $\begin{array}{c}0,76 \pm 0,06 \\
\mathrm{p}_{1}>0,1\end{array}$ & $\begin{array}{c}1,04 \pm 0,09 \\
\mathrm{p}_{1}<0,001\end{array}$ & $\mathrm{p}<0,001$ \\
\hline
\end{tabular}

Пр име ч а н ие : p - показатель достоверности отличий между группой сравнения и основной; $\mathrm{p}_{1}$ - показатель достоверности отличий по сравнению с исходным уровнем.

Таблица 2

\section{Содержание фосфора в ротовой жидкости детей на разных этапах ортодонтического} лечения, ммоль/л

\begin{tabular}{|l|c|c|c|}
\hline \multicolumn{1}{|c|}{ Сроки } & $\begin{array}{c}\text { Группа сравнения, } \\
\mathrm{n}=22\end{array}$ & $\begin{array}{c}\text { Основная } \\
\text { группа, } \\
\mathrm{n}=25\end{array}$ & $\mathrm{p}$ \\
\hline Исходный & $2,53 \pm 0,24$ & $2,84 \pm 0,26$ & $\mathrm{p}>0,1$ \\
\hline $\begin{array}{l}\text { Через 2 недели профилактики перед фикса- } \\
\text { цией пластинки }\end{array}$ & $\begin{array}{c}2,77 \pm 0,26 \\
\mathrm{p}_{1}>0,1\end{array}$ & $\begin{array}{c}3,21 \pm 0,29 \\
\mathrm{p}_{1}>0,1\end{array}$ & $\mathrm{p}>0,1$ \\
\hline Через 1 месяц после фиксации пластинки & $\begin{array}{c}2,79 \pm 0,19 \\
\mathrm{p}_{1}>0,1\end{array}$ & $\begin{array}{c}2,81 \pm 0,24 \\
\mathrm{p}_{1}>0,1\end{array}$ & $\mathrm{p}>0,1$ \\
\hline Через 6 месяцев после фиксации пластинки & $\begin{array}{c}2,74 \pm 0,25 \\
\mathrm{p}_{1}>0,1\end{array}$ & $\begin{array}{c}3,72 \pm 0,35 \\
\mathrm{p}_{1}<0,01\end{array}$ & $\mathrm{p}<0,01$ \\
\hline Через 1 год после фиксации пластинки & $\begin{array}{c}2,59 \pm 0,22 \\
\mathrm{p}_{1}>0,1\end{array}$ & $\begin{array}{c}3,66 \pm 0,27 \\
\mathrm{p}_{1}<0,005\end{array}$ & $\mathrm{p}<0,01$ \\
\hline Через 2 года после фиксации пластинки & $\begin{array}{c}2,83 \pm 0,21 \\
\mathrm{p}_{1}>0,1\end{array}$ & $\begin{array}{c}4,0 \pm 0,31 \\
\mathrm{p}_{1}<0,005\end{array}$ & $\mathrm{p}<0,005$ \\
\hline
\end{tabular}

Пр им е ч н и е : p - показатель достоверности отличий между группой сравнения и основной; $\mathrm{p}_{1}$ - показатель достоверности отличий по сравнению с исходным уровнем.

Таблица 3

Динамика изменения активности уреазы в ротовой жидкости детей в процессе ортодонтического лечения и применения лечебно-профилактического комплекса, мк-кат/л

\begin{tabular}{|l|c|c|c|}
\hline \multicolumn{1}{|c|}{ Сроки } & $\begin{array}{c}\text { Группа сравнения, } \\
\mathrm{n}=22\end{array}$ & $\begin{array}{c}\text { Основная группа, } \\
\mathrm{n}=25\end{array}$ & $\mathrm{p}$ \\
\hline \multicolumn{1}{|c|}{1} & 2 & 3 & 4 \\
\hline Исходный & $0,39 \pm 0,05$ & $0,48 \pm 0,07$ & $\mathrm{p}>0,1$ \\
\hline Через 2 недели профилактики перед фикса- & $0,15 \pm 0,03$ & $0,06 \pm 0,02$ \\
$\mathrm{p}_{1}<0,005$ & $\mathrm{p}<0,05$ \\
цией пластинки & $\begin{array}{c}0,22 \pm 0,07 \\
\mathrm{p}_{1}>0,1\end{array}$ & $\begin{array}{c}0,07 \pm 0,04 \\
\mathrm{p}_{1}<0,005\end{array}$ & $\mathrm{p}<0,001$ \\
\hline Через 1 месяц после фиксации пластинки & & \\
\hline
\end{tabular}


Продолжение таблицы 3

\begin{tabular}{|l|c|c|c|}
\hline 1 & 2 & 3 & 4 \\
\hline Через 6 месяцев после фиксации пластинки & $\begin{array}{c}0,27 \pm 0,04 \\
\mathrm{p}_{1}>0,1\end{array}$ & $\begin{array}{c}0,08 \pm 0,004 \\
\mathrm{p}_{1}<0,001\end{array}$ & $\mathrm{p}<0,005$ \\
\hline Через 1 год после фиксации пластинки & $\begin{array}{c}0,40 \pm 0,06 \\
\mathrm{p}_{1}>0,1\end{array}$ & $\begin{array}{c}0,09 \pm 0,002 \\
\mathrm{p}_{1}<0,001\end{array}$ & $\mathrm{p}<0,001$ \\
\hline Через 2 года после фиксации пластинки & $\begin{array}{c}0,49 \pm 0,05 \\
\mathrm{p}_{1}>0,1\end{array}$ & $\begin{array}{c}0,1 \pm 0,03 \\
\mathrm{p}_{1}<0,001\end{array}$ & $\mathrm{p}<0,05$ \\
\hline
\end{tabular}

Пр имечан ие : $\mathrm{p}$ - показатель достоверности отличий между группой сравнения и основной; $\mathrm{p}_{1}-$ показатель достоверности отличий по сравнению с исходным уровнем.

Таблица 4

Динамика изменения активности лизоцима в ротовой жидкости детей в процессе ортодонтического лечения с использованием лечебно-профилактического комплекса, ед/л

\begin{tabular}{|l|c|c|c|}
\hline \multicolumn{1}{|c|}{ Сроки } & $\begin{array}{c}\text { Группа сравнения, } \\
\mathrm{n}=22\end{array}$ & $\begin{array}{c}\text { Основная группа, } \\
\mathrm{n}=25\end{array}$ & $\mathrm{p}$ \\
\hline Исходный & $59,2 \pm 8,0$ & $\mathrm{p}, 0 \pm 6,7$ & $\mathrm{p}>0,1$ \\
\hline Через 2 недели профилактики перед фикса- & $\begin{array}{c}65,8 \pm 6,8 \\
\mathrm{p}_{1}>0,1\end{array}$ & $\mathrm{p}>0,1$ \\
цией пластинки & $\begin{array}{c}89,7 \pm 7,1 \\
\mathrm{p}_{1}<0,01\end{array}$ & $\begin{array}{c}114,0 \pm 0,2 \\
\mathrm{p}_{1}<0,001\end{array}$ & $\mathrm{p}<0,05$ \\
\hline Через 1 месяц после фиксации пластинки & $\begin{array}{c}78,0 \pm 10,0 \\
\mathrm{p}_{1}>0,1\end{array}$ & $\begin{array}{c}143,8 \pm 12,6 \\
\mathrm{p}_{1}<0,001\end{array}$ & $\mathrm{p}<0,001$ \\
\hline Через 6 месяцев после фиксации пластинки & $\begin{array}{c}69,6 \pm 9,3 \\
\mathrm{p}_{1}>0,1\end{array}$ & $\begin{array}{c}130,0 \pm 10,2 \\
\mathrm{p}_{1}<0,001\end{array}$ & $\mathrm{p}<0,001$ \\
\hline Через 1 год после фиксации пластинки & $\begin{array}{c}75,6 \pm 7,4 \\
\mathrm{p}_{1}>0,1\end{array}$ & $\begin{array}{c}106,2 \pm 14,0 \\
\mathrm{p}_{1}<0,001\end{array}$ & $\mathrm{p}<0,01$ \\
\hline Через 2 года после фиксации пластинки & & \\
\hline
\end{tabular}

Пр им еча н ие : $\mathrm{p}$ - показатель достоверности отличий между группой сравнения и основной; $\mathrm{p}_{1}-$ показатель достоверности отличий по сравнению с исходным уровнем.

Таблица 5

Динамика изменения содержание МДА в ротовой жидкости детей в процессе ортодонтического лечения и применения лечебно-профилактического комплекса, ммоль/л

\begin{tabular}{|l|c|c|c|}
\hline \multicolumn{1}{|c|}{ Сроки } & $\begin{array}{c}\text { Группа сравнения, } \\
\mathrm{n}=22\end{array}$ & $\begin{array}{c}\text { Основная группа, } \\
\mathrm{n}=25\end{array}$ & $\mathrm{p}$ \\
\hline Исходный & $0,41 \pm 0,04$ & $0,39 \pm 0,05$ & $\mathrm{p}>0,1$ \\
\hline Через 2 недели профилактики перед фикса- & $\begin{array}{c}0,32 \pm 0,03 \\
\mathrm{p}_{1}<0,05\end{array}$ & $\begin{array}{c}0,17 \pm 0,02 \\
\mathrm{p}_{1}<0,001\end{array}$ & $\mathrm{p}>0,1$ \\
цией пластинки & $\begin{array}{c}0,53 \pm 0,06 \\
\mathrm{p}_{1}>0,1\end{array}$ & $\begin{array}{c}0,21 \pm 0,03 \\
\mathrm{p}_{1}<0,001\end{array}$ & $\mathrm{p}<0,05$ \\
\hline Через 1 месяц после фиксации пластинки & $\begin{array}{c}0,36 \pm 0,04 \\
\mathrm{p}_{1}>0,1\end{array}$ & $\begin{array}{c}0,12 \pm 0,02 \\
\mathrm{p}_{1}<0,001\end{array}$ & $\mathrm{p}<0,005$ \\
\hline Через 6 месяцев после фиксации пластинки & $\begin{array}{c}0,47 \pm 0,05 \\
\mathrm{p}_{1}>0,1\end{array}$ & $\begin{array}{c}0,14 \pm 0,02 \\
\mathrm{p}_{1}<0,001\end{array}$ & $\mathrm{p}<0,001$ \\
\hline Через 1 год после фиксации пластинки & $\begin{array}{c}0,43 \pm 0,04 \\
\mathrm{p}_{1}>0,1\end{array}$ & $\begin{array}{c}0,18 \pm 0,03 \\
\mathrm{p}_{1}<0,001\end{array}$ & $\mathrm{p}<0,005$ \\
\hline Через 2 года после фиксации пластинки & &
\end{tabular}

Пр имечан ие: $\mathrm{p}$ - показатель достоверности отличий между группой сравнения и основной; $\mathrm{p}_{1}-$ показатель достоверности отличий по сравнению с исходным уровнем.

Маркером уровня перекисного окисления липидов (ПОЛ) был выбран малоновый диальдегид (МДА), содержание которого оценивалось на разных этапах лечения (табл. 5). Через 2 года наблюдения содержание МДА в ротовой жидкости у детей основной группы было в 2,2 раза ниже, чем в исходном состоянии, и в 2,4 раза ниже, чем в группе сравнения, что свидетельствует о снижении ПОЛ и о пародонтопротекторном эффекте ЛПК.

Для оценки состояния антиоксидантной защиты в полости рта мы использовали в слюне у 
детей активность фермента каталазы. На всех этапах динамического наблюдения видно, что у детей основной группы, получавших ЛПК, этот показатель превышал соответствующее значение у детей группы сравнения практически вдвое (табл. 6).

Степень воспалительного процесса в полости рта нами оценивалась по активности протео- литического фермента лейкоцитарного происхождения - эластазы. В основной группе этот показатель сохранялся на низком уровне на всех этапах наблюдения. Через 2 года активность эластазы в основной группе была достоверно ниже в 2,32 раза, чем в группе сравнения, и в 1,67 раза ниже, чем в исходном состоянии (табл. 7).

Таблица 6

Динамика изменения активности каталазы в ротовой жидкости детей в процессе ортодонтического лечения и применения лечебно-профилактического комплекса, мкат/л

\begin{tabular}{|l|c|c|c|}
\hline \multicolumn{1}{|c|}{ Сроки } & $\begin{array}{c}\text { Группа сравнения, } \\
\mathrm{n}=22\end{array}$ & $\begin{array}{c}\text { Основная } \\
\text { группа, } \\
\mathrm{n}=25\end{array}$ & $\mathrm{p}$ \\
\hline Исходный & $0,15 \pm 0,02$ & $0,17 \pm 0,01$ & $\mathrm{p}>0,1$ \\
\hline $\begin{array}{l}\text { Через 2 недели профилактики перед фикса- } \\
\text { цией пластинки }\end{array}$ & $\begin{array}{c}0,22 \pm 0,02 \\
\mathrm{p}_{1}<0,05\end{array}$ & $\begin{array}{c}0,34 \pm 0,03 \\
\mathrm{p}_{1}<0,001\end{array}$ & $\mathrm{p}<0,05$ \\
\hline Через 1 месяц после фиксации пластинки & $0,14 \pm 0,01$ & $\begin{array}{c}0,26 \pm 0,02 \\
\mathrm{p}_{1}<0,05\end{array}$ & $\mathrm{p}<0,01$ \\
\hline Через 6 месяцев после фиксации пластинки & $\begin{array}{c}0,17 \pm 0,02 \\
\mathrm{p}_{1}>0,1\end{array}$ & $\begin{array}{c}0,3 \pm 0,03 \\
\mathrm{p}_{1}<0,01\end{array}$ & $\mathrm{p}<0,01$ \\
\hline Через 1 год после фиксации пластинки & $\begin{array}{c}0,13 \pm 0,01 \\
\mathrm{p}_{1}>0,1\end{array}$ & $\begin{array}{c}0,32 \pm 0,04 \\
\mathrm{p}_{1}<0,01\end{array}$ & $\mathrm{p}<0,001$ \\
\hline Через 2 года после фиксации пластинки & $0,14 \pm 0,02$ & $0,29 \pm 0,03$ & $\mathrm{p}<0,01$ \\
\hline
\end{tabular}

Пр имечан ие : $\mathrm{p}$ - показатель достоверности отличий между группой сравнения и основной; $\mathrm{p}_{1}$ - показатель достоверности отличий по сравнению с исходным уровнем.

Таблица 7

Динамика изменения активности эластазы в ротовой жидкости детей в процессе ортодонтического лечения и применения лечебно-профилактического комплекса, мкат/л

\begin{tabular}{|c|c|c|c|}
\hline Сроки & $\begin{array}{c}\text { Группа сравнения, } \\
\mathrm{n}=22\end{array}$ & $\begin{array}{c}\text { Основная } \\
\text { группа, } \\
\text { n=25 }\end{array}$ & $\mathrm{p}$ \\
\hline Исходный & $2,43 \pm 0,18$ & $2,65 \pm 0,24$ & $\mathrm{p}>0,1$ \\
\hline $\begin{array}{l}\text { Через } 2 \text { недели профилактики перед фикса- } \\
\text { цией пластинки }\end{array}$ & $\begin{array}{c}1,68 \pm 0,13 \\
\mathrm{p}_{1}<0,005\end{array}$ & $\begin{array}{c}1,14 \pm 0,09 \\
\mathrm{p}_{1}<0,001\end{array}$ & $\mathrm{p}<0,001$ \\
\hline Через 1 месяц после фиксации пластинки & $\begin{array}{c}3,24 \pm 0,23 \\
\mathrm{p}_{1}>0,1\end{array}$ & $\begin{array}{l}1,79 \pm 0,14 \\
\mathrm{p}_{1}<0,005\end{array}$ & $\mathrm{p}<0,05$ \\
\hline Через 6 месяцев после фиксации пластинки & $\begin{array}{c}1,90 \pm 0,15 \\
\mathrm{p}_{1}<0,05\end{array}$ & $\begin{array}{c}1,36 \pm 0,15 \\
\mathrm{p}_{1}<0,001\end{array}$ & $\mathrm{p}<0,05$ \\
\hline Через 1 год после фиксации пластинки & $\begin{array}{c}3,45 \pm 0,18 \\
\mathrm{p}_{1}>0,1\end{array}$ & $\begin{array}{c}1,29 \pm 0,13 \\
\mathrm{p}_{1}<0,001\end{array}$ & $\mathrm{p}<0,001$ \\
\hline Через 2 года после фиксации пластинки & $\begin{array}{c}3,68 \pm 0,30 \\
\mathrm{p}_{1}>0,1\end{array}$ & $\begin{array}{l}1,58 \pm 0,17 \\
\mathrm{p}_{1}<0,001\end{array}$ & $\mathrm{p}<0,001$ \\
\hline
\end{tabular}

Пр име чан ие : p - показатель достоверности отличий между группой сравнения и основной; $\mathrm{p}_{1}$ - показатель достоверности отличий по сравнению с исходным уровнем.

Bbыводы. Проведенные исследования показали, что разработанный ЛПК, включавший адаптоген «Леквин», набор витаминов и микроэлементов «Пиковит плюс», гель «Квертулидон» и зубной эликсир «Лизодент», при лечении ЗЧА у детей со средним кариесом зубов с использованием съёмных аппаратов обладает выраженным минерализующим, антиоксидантным и регули- рующим микробиоценоз действием. При этом в ротовой жидкости детей основной группы за 2 года наблюдений достоверно увеличивались по сравнению с исходным состоянием и группой сравнения содержание Са и Р, активность лизоцима, каталазы и уменьшались активность уреазы, эластазы и содержание МДА. 


\section{Список литературы}

1. Репужинский И.М. Влияние съемной и несъемной ортодонтической аппаратуры на гигиену полости рта и состояние тканей пародонта у детей: автореф. дисс. на соискание учен. степени канд. мед. наук : спец. 14.00.21 «Стоматология» / И. М. Репужинский - Одесса, 2002. -20 с.

2. Деньга А.Э. Биохимические параметры ротовой жидкости у детей с начальным кариесом зубов в процессе комплексного ортодонтического лечения / А. Э. Деньга, О. А. Макаренко // Вісник стоматології. - 2013. - № 3. - С. 5862 .

3. Левицкий А.П. Биохимические маркеры воспаления тканей ротовой полости [методические рекомендации] / [А.П. Левицкий, О.В. Деньга О.А. Макаренко и др.]. - Одесса: КП «Одеська міська друкарня», 2010. - 15с.

4. Гирин С.В. Модификация метода определения активности каталазы в биологических субстратах / С. В. Гирин // Лаб. диагностика. - 1999. - № 4. - С.45 - 46.

5. Левицкий А.П. Ферментативный метод определения дисбиоза полости рта для скрининга про- и пребиотиков [метод. рекомендации] / [А.П. Левицкий, О.А. Макаренко, И.А. Селиванская и др.]. - Киев, 2007. - 22 с.

6. Горячковский А.М. Клиническая биохимия в лабораторной диагностике [справочное пособие] / А. М. Горячковский [изд. 3-е вып. и доп.].- Одеса: Екологія, 2005. С. 402 - 412. (кальций, фосфор).

7. Левицкий А.П. Лизоцим вместо антибиотиков / Левицкий А.П.. - Одесса : КП ОГТ, 2005. - 74 с.

8. Гаврикова Л.М. Уреазная активность ротовой жидкости у больных с острой одонтогенной инфекцией челюстно-лицевой области / Л.М. Гаврикова, И.Т. Сегень // Стоматология. - 1996. - Спец. вып. - С. 49-50.

9. Шинкевич В.И. Аргументы за и против назначения препаратов кальция детям с целью профилактики кариеса / В.И. Шинкевич // Современная стоматология.2012.- № 5.- С.48.

\section{REFERENCES}

1. Repuzhinskiy I.M. Vliianie sieemnoi $i$ nesieemnoi ortodonticheskoi apparatury na gigienu polosti rta i sostoianie tkanei parodonta $u$ detei [Influence of removable and nonremovable orthodontic equipment on oral hygiene and the condition of periodontal tissues in children]. Abstract of a candidate's thesis of medical sciences. Odessa; 2002:20.

2. Denga A.E., Makarenko O.A. Biochemical parameters of oral fluid in children with initial dental caries in the process of complex orthodontic treatment. Visnyk stomatolohiyi. 2013;3:58-62.

3. Levickij A.P., Den'ga O.V., Makarenko O.A. Biohimicheskie markery vospalenija tkanej rotovoj polosti [Biochemical markers of inflammation of the oral cavity]. Odessa, KP “Odes'ka mis'ka drukarnya", 2010: 15.

4. Girin S.V. Modification of the method for determining the activity of catalase in the biological substrates. Laboratornaja diagnostika. 1999;4:45-46.

5. Levickij A.P., Makarenko O.A., Selivanskaja I.A., Rossahanova L.N., Den'ga O.V., Pochtar' V.N., Skidan K.V., Goncharuk S.V. Fermentativnyj metod opredelenija disbioza polosti rta dlja skrininga pro- i prebiotikov [Fermentative method for the determination of dysbiosis oral screening pro- and prebiotics]. Kiev, 2007: 22.

6. Gorjachkovskij A.M. Klinicheskaja biohimija $v$ laboratornoj diagnostike [Clinical chemistry in the laboratory diagnosis]. Odessa, 2005: 402-412.

7. Levickij A.P. Lizotsim vmesto antibiotikov [Lysozyme instead of antibiotics] Odessa, KP "Odes'ka mis'ka drukarnya", 2005: 74 .

8. Gavrikova L.M., Segen' I.T. Urease activity of the oral fluid in patients with acute odontogenic infection of the maxillofacial region. Stomatologiya. 1996; Special issue: 49-50.

9. Shinkevich V.I. Arguments for and against the prescription of calcium preparations for children with the aim of preventing caries. Sovremennaya stomatologiya. 2012;5:48. 